\title{
Western Faculty Profile: Dr. Miguel Valvano
}

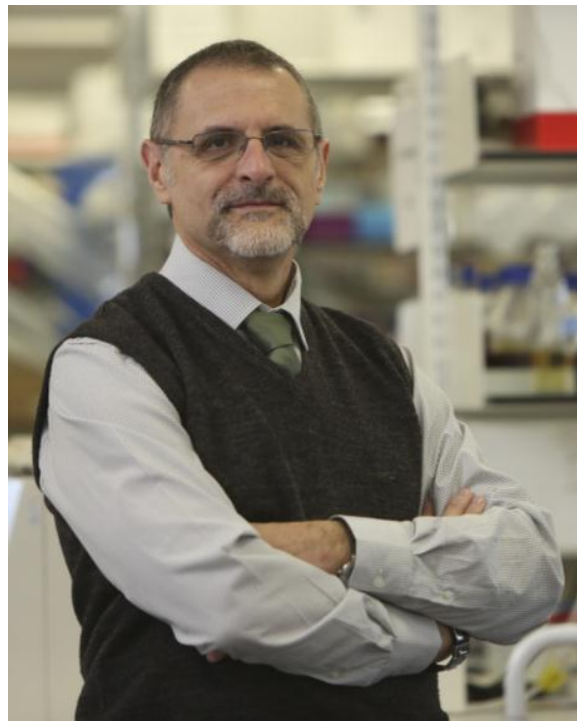

\section{Background}

Dr. Miguel Valvano is a Professor Emeritus in the Department of Microbiology and Immunology at Western University. He also holds an academic Chair of Microbiology and Infectious Diseases at the Centre for Infection and Immunity, Queen's University Belfast, United Kingdom. His laboratory has become an international leader in molecular research aimed at dissecting key bacterial components that directly interact with host cells to cause infections. His research team focuses on two areas: how lipopolylsaccharide (LPS) assembles on the bacterial cell surface and protects bacteria from host defenses, and characterizing the virulence properties of Burkholderia cepacia, an opportunistic pathogen that causes major health problems in patients suffering from cystic fibrosis. Suzy Kim, a member of WURJ, had the opportunity to interview Dr. Valvano to learn more about his research, his path to Western and his career.

\section{Questions for Dr. Valvano}

\section{Tell us about yourself.}

I am a Professor of Microbiology and Immunology at Western, former Tier 1 Canada Research Chair in Infectious Diseases and Microbial Pathogenesis, and currently a Professor of Microbiology and Infectious Diseases at Queen's University Belfast in the U.K. Having trained as a pediatrician in Argentina, I was initially interested in pediatric infectious diseases, but my interest expanded into general infectious diseases. I also trained as a research fellow for five years at the Oregon Health Sciences University before coming to Western.

\section{What is your main research focus in your lab?}

My research is in the mechanisms of pathogenicity and how bacteria can cause infection. Specifically, our focus is on lipopolysaccharide (LPS), a key molecule in Gram-negative bacteria that provides protection to bacteria. We are looking at intrinsic microbial resistance and molecular pathogenesis of an opportunistic pathogen related to cystic fibrosis. We work with Burkholderia cenocepacia, and our lab made major contributions to this field by developing genetic tools now used worldwide, and also by discovering that this organism can survive in macrophages. 


\section{Why did you choose the field of microbiology and immunology? What sparked your interest in the field of opportunistic bacteria?}

I am excited about how bugs cause disease in general, but more so I have a passion for research. The feeling of being right at the edge of the known and unknown is thrilling, as well as making discoveries when there is no laid out path. I also like challenge: trying to figure out how things work in cells or how bacteria interact with other organisms, and these areas ignited my passion and interest in discovering new things.

\section{What made you choose Western University as opposed to other academic institutions?}

When I applied to Canada, I was a foreigner, and Western was one of the several universities I considered. After my job interview here, I felt very comfortable, and also brought microbial molecular genetics, which was something new to this department at the time. So I took advantage of this great opportunity.

\section{In your opinion, what are qualities of an excellent researcher?}

Researchers are excited about what they do and the questions that come up. It's not just about doing the experiment, but also thinking about the experiment, thinking about the hypothesis, and looking for ways to find new things when we don't know how to approach it. An excellent researcher is a good coach, a professional writer, and a good communicator. You have to be able to collaborate with others and help them develop in the context of research. Always try to be creative, which is not a simple process, but which good coaching can help. You need to be a professional writer in writing grant proposals, and in bringing your work to perspective. A good ability to communicate at all levels is critical as well. You also have to be patient, and have to be able to tolerate frustration, as it may be difficult to obtain the results that you want.

\section{What would you say is the hardest part about being a researcher? And the best part?}

The hardest part is tolerating frustration, accepting that someone is going to review your publication and say that your work is not up to quality, or not receiving funding of your proposals. It can be difficult to accept those comments in a constructive way. The best part for me is the excitement, the ability to travel the world, connecting with the worldwide community and interacting with a network of scientists. They know you, you know about their work, it is a huge community and we all have similar expectations and hopes. Discovery is another thing. Unravelling something that was not known before, regardless of how small the contribution is, can be very pleasing. Seeing a trainee start in the lab and through training, become independent in approaching research, is also very fulfilling.

\section{What advice would you give an undergraduate student interested in getting involved in research?}

Research is perceived as being difficult mainly due to gloomy funding situations with many countries not supporting research. Someone interested in research has to be highly motivated, needs good mentors, and has to do some soul searching. You also need to have "fire in your belly", meaning a passion for discovery and for a life of excitement involving research. If you have this, along with good opportunities and mentorship, and if you can take the frustration of not being funded initially and being rejected, then you may have a great opportunity to succeed. Another thing is to not be overfocused in research. People get too focused and lose the view of surroundings, and it is important to try to develop a type of thinking that encompasses other approaches and a better understanding of other aspects. Also try to participate in seminars, talk to visiting scientists, go meet people, ask questions about what they do as they will provide extensive information to future scientists. 


\section{What qualities do you look for in a potential research assistant?}

At any level, I want dedication, passion for research, someone who understands what it means to be in a team and is willing to set aside time for helping others. I want someone who is prepared to tolerate hardships and frustration in research. It is important being able to balance research with controls and engage in a process that is constant in forming a hypothesis, testing hypotheses, conducting the experiments, interpreting results, and then moving onto the next question. It is a slow process, but in the end very rewarding.

\section{What do you believe will be the future of research in bacterial pathogenesis?}

It is difficult to predict it when it comes to understanding the detailed, fine interactions between a host and a pathogen. However, I suspect a better understanding of the role played by bacteria in daily life is paramount. Future research will certainly contribute to the understanding of the microbiome in general, such as the realization that microbes or bacteria interact with molecules from the environment. They could be molecules from inside or outside the host, such as in soil and water, and these are major influences in how bacteria respond. When bacteria live in a host, they are trained so they respond the same way in the environment. With emerging molecular genetics, there will be novel discoveries in areas such as synthetic biology, where we will be able to reconstruct new metabolic pathways that enable microorganisms to produce molecules for humans in a relatively cheap way.

To read more on Dr. Valvano's lab and research, please visit his website at: http://publish.uwo.ca/ mvalvano/ 